\title{
Study on the fluorescence properties of the interaction between felodipine and bovine serum protein
}

\author{
Shuxian $\mathrm{Li}^{1}$, Jialuo $\mathrm{Bu}^{1}$, Wenbin $\mathrm{Liu}^{2}$, Cuijuan $\mathrm{Liu}^{1}$, and Yuguang $\mathrm{Lv}^{1, *}$ \\ ${ }^{1}$ College of Pharmacy, Jiamusi University, Jiamusi, China \\ ${ }^{2}$ School of materials science and Engineering, Jiamusi University, Jiamusi, China
}

\begin{abstract}
The interaction between felodipine and bovine serum protein was studied, the optimal experimental conditions were selected, and the fluorescence quenching mechanism was discussed.The interaction between filodipine and bovine serum protein was determined by UV spectrophotometry, and the optimal experimental conditions were selected by control variable method. The mechanism of fluorescence quenching in the system was explored by fluorescence spectrophotometry.The fluorescence intensity of the system between felodipine and bovine serum protein was the most obvious under the experimental conditions of buffer solution $\mathrm{pH} 7.4$, felodipine concentration $8.0^{*} 10^{-4} \mathrm{~mol} / \mathrm{L}$, reaction time $30 \mathrm{~min}$ and $25^{\circ} \mathrm{C}$.Static fluorescence quenching caused by the formation of complex compounds.
\end{abstract}

Keywords: Bovineserumprotein; Felodipine; Complex; Fluorescence properties study.

\section{Introduction}

At present, the main drugs used for the treatment of hypertension include the following categories: diuretics, $\beta$-blockers, and calcium inhibitors ${ }^{[1-4]}$. Diuretics reduce blood pressure by increasing the amount of urine the body excretes sodium ions from the body. Its antihypertensive effect is mild and lasting, effective for a long time, and it is not easy to produce drug resistance. These drugs can be used independently to treat various types of hypertension. $\beta$-blockers, which reduce blood pressure by blocking the number of $\beta$ receptors entering cells, are more suitable for the treatment of hypertension with high excretion ${ }^{[5]}$. Calcium antagonists reduce blood pressure by blocking the flow of extracellular calcium ions into arterial smooth muscle cells, thereby reducing resistance in surrounding blood vessels, selectively dilating arterial cells to increase excess blood flow. Commonly used drugs mainly include nifedipine and felodipine ${ }^{[6]}$, which are suitable for patients with coronary heart disease or peripheral vascular disease. It has a good effect on hypertension in the elderly.

Felodipine is a second-generation dihydropyridine $\mathrm{Ca}^{2+}$ channel blocker type antihypertensive drug introduced by a Swiss company in 1998, which can selectively

\footnotetext{
*Corresponding author: yuguanglv@163.com
} 
reduce the activity and contractile force of peripheral arterioles ${ }^{[7-9]}$. In the medical field, most scholars believe that felodipine is the most ideal drug for the treatment of hypertension by far through clinical experimental tests.

Serum protein is the most water-soluble plasma protein in human blood, which can interact with some substances and dissolve in blood and play a corresponding role as the blood system is transported to the whole body. For example, the reversible binding reaction between hormone and albumin can achieve a relatively stable albumin concentration ${ }^{[10-12]}$.

\section{Results and discussion}

\subsection{Study results of interaction between felodipine and bovine serum protein}

BSA is an endogenous fluorescent substance, because its molecules contain tryptophan and other amino acid residues, these amino acid residues can emit strong fluorescence. As shown in Figure 3-1, when the BSA concentration remained constant, the dosage of felodipine was increased, but the position of its maximum emission peak and the shape of the peak basically did not change significantly compared with the original shape. This is typical of fluorescence quenching. Therefore, the interaction between felodipine and bovine serum protein can be demonstrated.

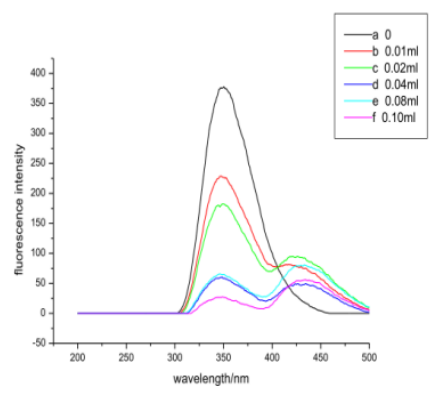

Fig. 1. Spectral image of bovine serum protein interacting with felodipine solutions at different dosations.

As can be seen from Figure 1, with the increase in the amount of felodipine standard solution, the endogenous fluorescence of BSA decreased regularly, but the position and shape of its maximum emission peak did not change basically, which was a symbolic phenomenon of fluorescence quenching, indicating the interaction between felodipine and bovis serum protein.

\subsection{Test results of blank experiment}

Under these conditions, The blank solvent had no obvious effect on the main absorption peaks of fluorescence intensity, the determination of felodipine standard solution is not affected by impurities. This blank control method has a good phenomenon, which is convenient for the experiment and the observation of image results. Fluorescence patterns of blank reagent, fluorescence systems of the standard solution containing felodipine and the sample solution containing felodipine sample solution of the same concentration are shown below.(The concentration of felodipine solution was $\left.2 \times 10^{-4} \mathrm{~mol} \cdot \mathrm{L}^{-1}\right)$.It can be seen from Figure 2 that The fluorescence intensity of the system was little affected by the blank solvent. 


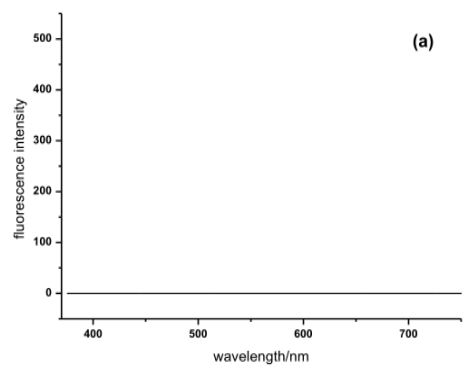

Fig. 2 Effect of blank solvent on fluorescence intensity of the system. A: Blank solvent.

Figure 3 shows the content determination of felodipine standard solution was also not affected by impurities.

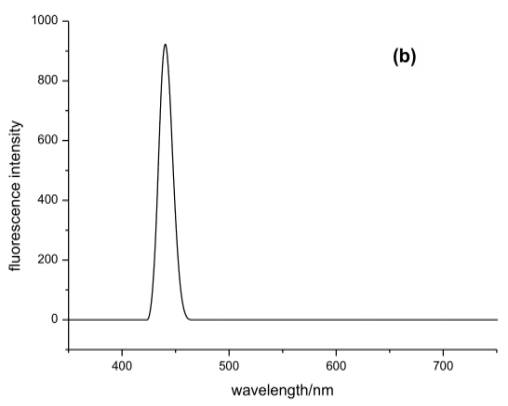

Fig. 3. Influence of impurity on fluorescence intensity standard solution of felodipine Fig. B: Impurity.

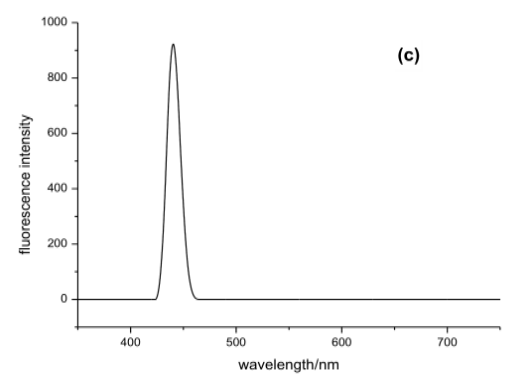

Fig. 4. Image of fluorescence intensity of felodipine sample solution with the same concentration C: felodipine sample solution with the same concentration.

\subsection{Ultraviolet spectrometric results}

Figure 5 shows the influence of felodipine concentration on the absorbance of the system. It can be seen that With the increase of felodipine concentration, the absorbance of the system increased continuously and presents a blue shift. This indicates that felodipine interacts with BSA, making tyrosine and tryptophan inside the protein exposed in a large number of polar solvents, and strengthening the absorption peak of the system. As the hydrophobic interaction between hydrophobic groups is relatively reduced, the energy of $\pi$ - $\pi^{*}$ transition increases, resulting in blue shift of absorption peak.

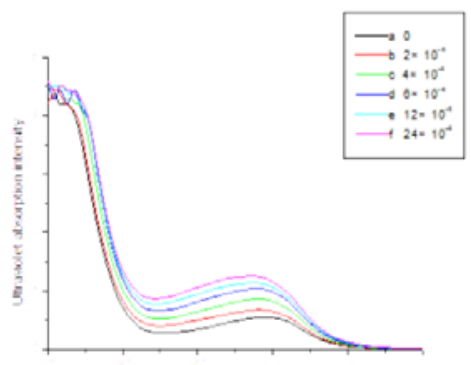

Fig. 5. Influence of felodipine standard solution concentration on absorbance of the system. 
As can be seen from Fig. 5, the concentration of felodipine standard solution $\left(0.2 \times 10^{-4}\right.$, $4 \times 10^{-4}, 6 \times 10^{-4}, 12 \times 10^{-4}$ and $\left.24 \times 10^{-4}\right)$ increased continuously, and the absorbance of the system increased continuously, showing blue shift phenomenon. The results showed that BSA interacted with felodipine, and the enhanced absorption peak was due to the interaction that resulted in a large amount of exposure of tyrosine and tryptophan inside the protein to polar solvents.

\subsection{Screening of optimal experimental conditions}

Figure 6 shows, during reaction time, response value of fluorescence intensity of the system gradually becomes stable and becomes more stable after $30 \mathrm{~min}$ of reaction. Therefore, the test was carried out after $30 \mathrm{~min}$ of reaction. In addition, in order to facilitate the experiment, the test was carried out at room temperature $\left(25^{\circ} \mathrm{C}\right)$. The fluorescence intensity of the system between felodipine and bovine serum protein was the most obvious under the experimental conditions of buffer solution $\mathrm{pH} 7.4$, felodipine concentration $8.0^{*} 10^{-4} \mathrm{~mol} / \mathrm{L}$, reaction time $30 \mathrm{~min}$ and $25^{\circ} \mathrm{C}$. Static fluorescence quenching caused by the formation of complex compounds.

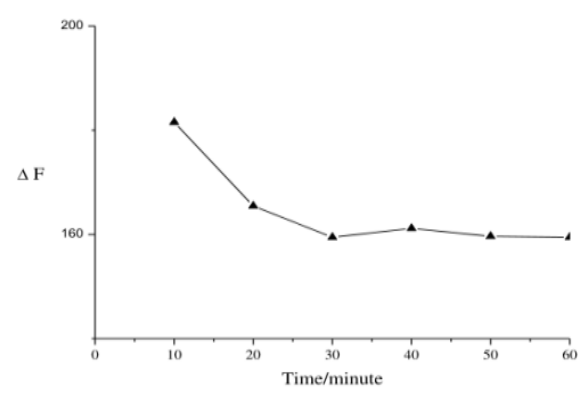

Fig. 6. Image of the measuring treaction effect time on the response value of the system.

\section{Conclusion}

In this experiment, the fluorescence properties of felodipine bovine serum protein complex interaction were studied. Through the experiment, it was found that felodipine bovine serum protein can interact with each other. Bovine serum protein contains residues such as tryptophan and tyrosine, which is endogenous fluorescence substance and can emit strong fluorescence. UV spectrophotometry showed that at a certain concentration of bovine serum protein, The endogenous fluorescence intensity of bovine serum protein decreased regularly with the increase of felodipine concentration, but the position and shape of its maximum emission peak did not change, which was the standard phenomenon of fluorescence quenching .In addition, three experiments with control variables were conducted to screen and determine optimum experimental conditions for the fluorescence properties of felodipine interacting with bovine serum protein.

In addition, the mechanism of fluorescence quenching in this system was explored, and whether the fluorescence quenching of the system was caused by static quenching or dynamic collision. It was found that the main cause of BSA quenching was the static quenching caused by the interaction between felodipine and bov serum protein to form a complex, rather than the dynamic collision. 


\section{References}

1. National Center for Cardiovascular Diseases. Cardiovascular Health and Disease Report 2019 M. Beijing: Science Press,2020.

2. S.N. li, Analysis of the status of elderly hypertension in China J. Chinese Journal of Hypertension, 2019, 2(27): 2.

3. Y.J. Mao, H. Jiang, L. Wang, et al. Progress in the diagnosis and treatment of renal damage in hypertension J. Medical review, 2019, 25(10): 1965-1969.

4. G.L. Liu, J. Liu, W.J. Shen,. Pharmacology and clinical application of felodipine, a novel calcium channel blocking agent J. 2018, 4(05): 176.

5. W. Zhong, Pharmacological action and clinical application of felodipine [J]. Chinese National Folk Medicine, 2017, 3(07): 245.

6. Y.F. Shen, L.G. Chang, Pharmacological effect and clinical application of felodipine J. Journal of Traditional Chinese Medicine, 2018, 33(01): 1-8.

7. D.N. Sun, Pharmacological analysis and clinical application of felodipine J. China Modern Drug Application, 2017, 11(15): 105-107.

8. G.F. Sun, Clinical effect of felodipine in the treatment of chronic congestive heart failure J. China Health Standard Management, 2020, 11(15): 85-87.

9. Z.F. Li, Study on the therapeutic effect of felodipine combined with valsartan in outpatient treatment of hypertension J. Chinese community physician, 2018, 34(36): 44-45.

10. J. Guan, X. Y An, Y . Zhao. Binding studies of triclocarban with bovine serum albumin: Insights from multi-spectroscopy and molecular modeling methods, Spectrochim. Acta. A 2018 (202): 1-12.

11. H.L. Zhou, Study on the interaction between several essential oil small molecules and bovine serum protein D. Guangzhou: Guangdong University of Technology, 2019, 37(5): 103-105.

12. Y.X. Zhang, Y. Zhang, The function and study of serum protein J. Journal of Hainan University Natural Science Edition, 2017, 25(3): 315-320. 